\title{
Efficacy of vitamin D in children with pneumonia: a randomized control trial study
} Dhungel A², Alam MS²

Department of Pediatrics, King Edward Medical University, Lahore, Pakistan

${ }^{1}$ Assistant Prof, Department of Pediatrics, King Edward Medical University

${ }^{2}$ Consultant, Department of Pediatrics. King Edward Medical Universitv

\begin{abstract}
Background and Objectives: Pneumonia is the inflammation of parenchyma of lungs. It strictly represents any inflammatory condition that involves the lungs along with the visceral pleura, airways, alveoli, connective tissues and vascular structures. The objective of the study was to see the efficacy of vitamin D in children with pneumonia.

Material and Methods: A randomized control study was conducted in Department of Pediatric Medicine, Mayo Hospital, Lahore, Pakistan. One hundred patients with pneumonia received vitamin $\mathrm{D}$ along with appropriate antibiotics and one hundred were treated with antibiotics but without vitamin D. The patients were discharged after the fast breathing and chest in drawing settled. The duration of hospital stay was noted. They were followed up for next 90 days after discharge from hospital and any new episode of pneumonia was noted and recorded.

Results: The mean number of days to recovery were similar between the group receiving vitamin $\mathrm{D}(5.7 \pm 2.7$ days $)$ and the group not receiving vitamin $\mathrm{D}(6.1 \pm 2.8$ days $),(\mathrm{p}=0.28)$. While comparing repeat episode of pneumonia within next three months, the repeat episode of pneumonia was significantly lower in the intervention group (2\%) than the group without supplementation ( $9 \% ; p=0.002)$ within 30 days of supplementation of vitamin D.

Conclusion: Vitamin D supplementation in a single dose to the children diagnosed as pneumonia significantly reduces the occurrence of new episodes of pneumonia within one month of discharge.
\end{abstract}

Key Words: Vitamin D, Pneumonia, dose

\section{INRODUCTION}

Pneumonia in children plays a significant role in morbidity and mortality in the developing countries [1]. According to the estimation of the World Health Organization (WHO) nearly 156 million cases of pneumonia occurs every year in children of less than five years age and among this at least 20 million cases are serious enough requiring admittance to the hospital [2]. Of these total cases, developing countries account for 151 million cases and around $7-13 \%$ are serious enough to 
endanger the life of a child without appropriate treatment.

Pneumonia is the largest single cause of death in children less than five years of age, and is responsible for nearly 1.4 million deaths every year (18\% of the total deaths) $[3,4]$. Each year approximately 91,000 children die in Pakistan from pneumonia which contributes to $19 \%$ of deaths under-five children of the country $[5,6]$. Even though the prevalence of pneumonia amongst underfive children is high in the country, only about half of them with pneumonia in Pakistan get proper antibiotic whereas $31 \%$ receive no treatment for pneumonia due to various reasons [6]. The Pakistan Demographic and Health Survey (PDHS) report from showed children aged 6-23 months were more likely to have symptoms of ARI than children in the older age groups. Children in households where charcoal was used as a cooking fuel were more likely to have symptoms of ARI than children in households using wood or straw and those using liquid petroleum gas or natural gas. It shows the increased incidence of pneumonia with indoor pollution [5].

Children with vitamin D deficiency and rickets are more likely to have pneumonia and respiratory tract infections [7]. On exposure of the human skin to UBV light from the sun, it synthesizes most of the vitamin D required in the body. Other sources are egg yolk, fatty fish such as tuna, sardines or cod liver oil $[8,9]$. Daily recommended dose of Vit D is $400 \mathrm{IU}$ in children. For the treatment of rickets its dose is 300,000 IU and 600,000 IU for children aged less than 1 year and more than one year respectively and for respiratory tract infection its dose is 100,000 IU [10]. Vitamin D has been shown to be effective in increasing the immunity and reducing the incidence of respiratory tract infections as shown by several studies $[9,11]$. Therefore, this study is carried out to determine the effect of vitamin D supplementation on duration of hospitalization in children with pneumonia and on the recurrence of pneumonia within 90 days of discharge.

\section{MATERIALS AND METHODS}

Patients of age 2 to 60 months of both sexes admitted to the Department of Pediatric Medicine, Mayo Hospital, Lahore through its emergency/OPD from December 2014 to May 2015, and fulfilling the definition of Pneumonia were included in the study subjects. After getting the informed consent from the parent/guardian of the patients, the demographic data were obtained. Detailed history about the symptoms and the duration of disease were taken. General physical and systemic examination was carried out and relevant investigations were sent along with vitamin D level. All the children with normal vitamin D level (i.e. more than 20 nanogram per milliliter) were excluded from the study. Patients meeting following exclusion criteria were excluded from the study.

\section{Exclusion criteria}

- Children with very severe disease

- Children with chronic respiratory diseases like asthma, tuberculosis (from history and clinical findings)

- Children with known heart disease or suspected on clinical findings

- Children who have received oral or intramuscular high dose $(300,000$ units for children of 2 to 12 months and 600,000 units for age 12 to 60 months) vitamin $\mathrm{D}$ treatment in last three months

- Children with PCM III (Protein Calorie Malnutrition grade III defined as 
weight for age $<60 \%$ as Gomez classification)

- Children with normal vitamin D level (more than $20 \mathrm{ng} / \mathrm{ml}$ )

The patients were randomly divided into two groups group A and group B. Both groups were treated with appropriate antibiotics for pneumonia. Group A patients in addition were given intramuscular vitamin D 100,000 units within the first 24 hours of admission whereas patients in group $B$ did not receive vitamin $\mathrm{D}$. The improvement of the child was monitored daily and he/she was discharged if there was no fast breathing and chest indrawing. The duration of stay at the hospital was recorded. All the information was collected on a specially designed proforma. The patients were followed up monthly for 3 months after discharge to assess for repeat episodes of pneumonia. The follow up was done mainly through telephone contact or at follow up clinic.

Data were entered and analyzed through SPSS (Statistical Package for Social Science) version 20. Numerical data were entered as it is but the qualitative data (categorical data) were codified and then were entered in SPSS. Analysis was done using chi-square test for categorical variables and $t$ - test for continuous variables. P-value was taken as less than 0.05 to be significant. The stratification of data was done on the basis of antibiotics received, i.e. the total sample was analyzed separately for outcomes of different antibiotics used. In this way the bias probably occurring due to different antibiotics was also checked.

\section{RESULTS}

The mean age of patient was $7.5 \pm 10.6$ months (Mean age of Interventional group was $8.1 \pm 11.0$ years and of placebo group was $6.9 \pm 10.1$ years). In both intervention and placebo group numbers of patients were equally distributed. Sixty one percent were male and $39 \%$ were female.

\section{Figure 1: Symptoms during admission}

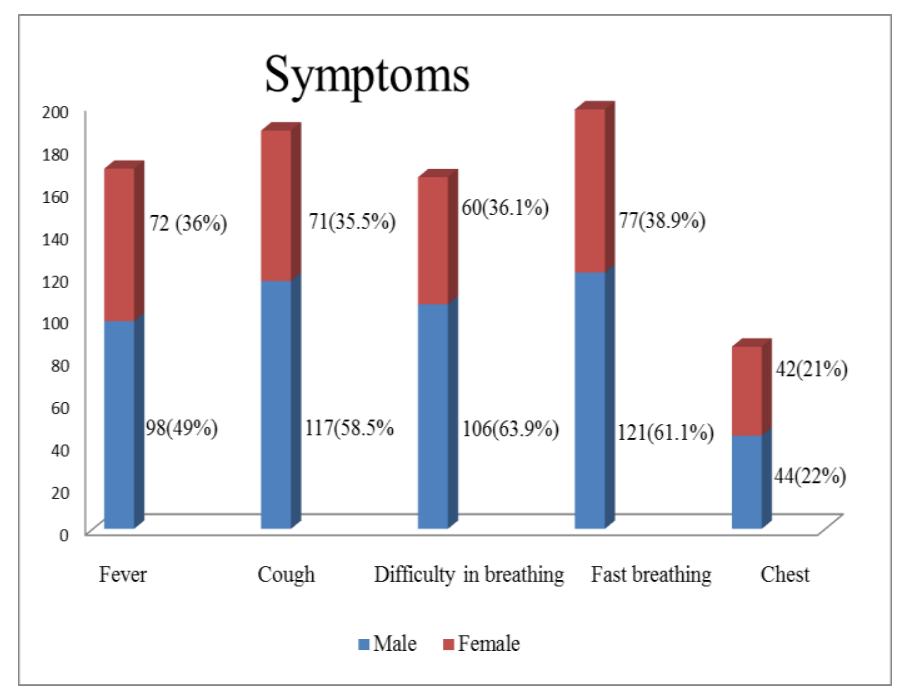

\section{Figure 2: Respiratory findings during admission}

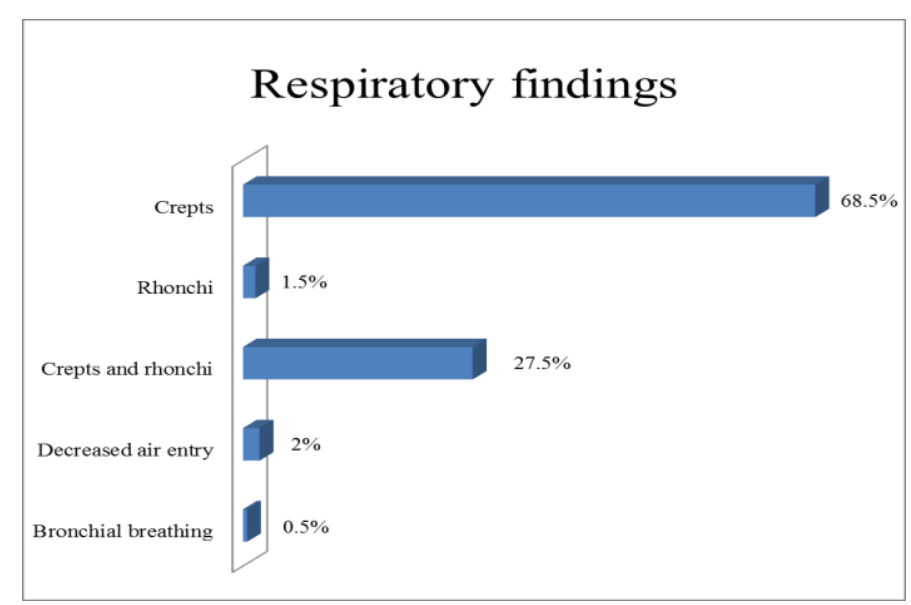

Figure 1-4 and table 1 show the clinical findings of the patients. Majority of patient had fast breathing (99\%) whereas 43\% patients had chest indrawing. Besides these two, cough topped the list with $94 \%$ children presenting with it. 
Fever contributed to $85 \%$ of symptoms. Depending on gender distribution symptoms distribution was fairly equal (figure 1).

Figure 2 shows auscultatory findings of the patients. Majority of the patients had crept (68.5\%) as respiratory findings in both the sexes whereas bronchial breathing contributed least as a symptomatology. None had normal respiratory findings.

Nutritional status is shown in figure 3. More than one third patients had no malnutrition whereas a quarter had grade I malnutrition and nearly $40 \%$ had grade II malnutrition. There was no significant difference in nutritional status in terms of gender (Figure $3)$.

\section{Figure 4: Chest $X$-ray findings of the patients}

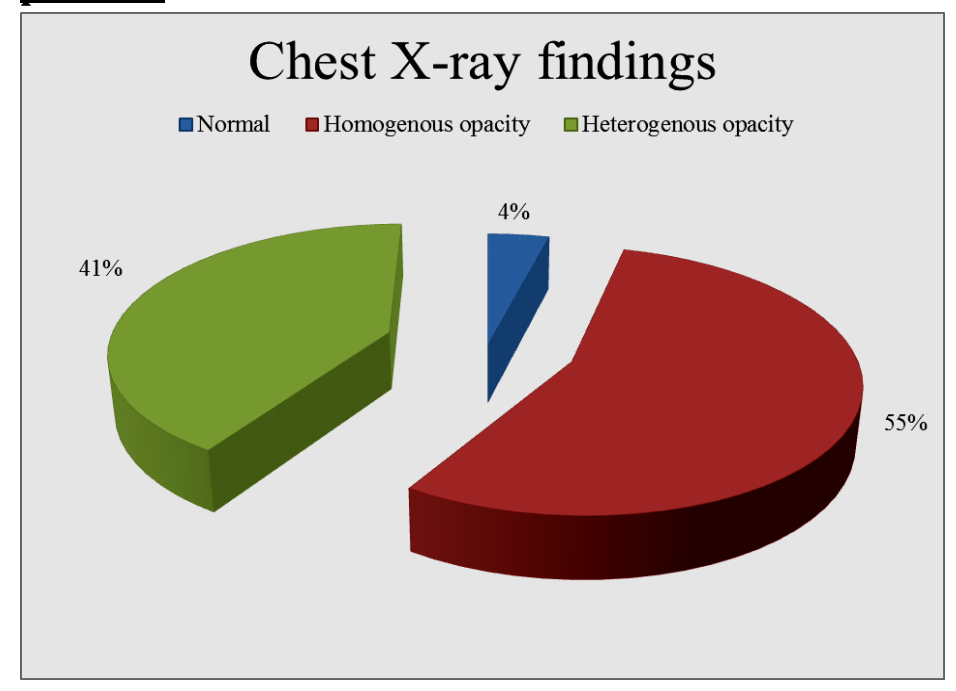

Table 1: showing illness duration and respiratory rate of the patients

\begin{tabular}{||c|c|c|c|c|c|c|c|c|c|}
\hline \multirow{2}{*}{ Parameters } & \multicolumn{3}{|c|}{ Mean \pm SD } & \multicolumn{3}{c|}{ Median } & \multicolumn{2}{c|}{ Range } \\
\cline { 2 - 10 } & male & female & Total & male & female & Total & male & female & Total \\
\hline $\begin{array}{c}\text { Illness } \\
\text { duration }\end{array}$ & $3.5 \pm 1.6$ & $3.5 \pm 1.6$ & $3.5 \pm 1.6$ & 3.0 & 3.0 & 3.0 & $1-8$ & $1-8$ & $1-8$ \\
\hline $\begin{array}{c}\text { Respiratory } \\
\text { rate }\end{array}$ & $66.0 \pm 5.6$ & $64.2 \pm 7.2$ & $65.3 \pm 6.3$ & 68 & 68 & 68 & $48-76$ & $46-76$ & $46-76$ \\
\hline
\end{tabular}

\section{Figure 3: Nutritional Status of the patient}

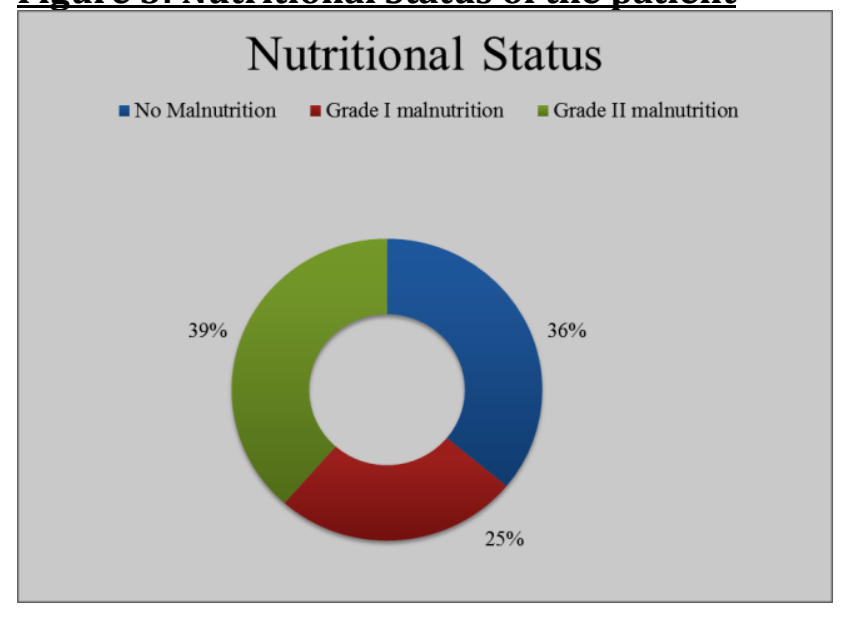

More than half of the patients (55\%) had homogenous opacity in their X-ray and only $4 \%$ had normal chest X-ray findings (Figure 4)

Table 1 depicts the illness duration before hospital visit and respiratory rate of the patients.

Both the intervention and non-intervention groups had received similar antibiotics. The use of antibiotics is shown in Figure 5. 


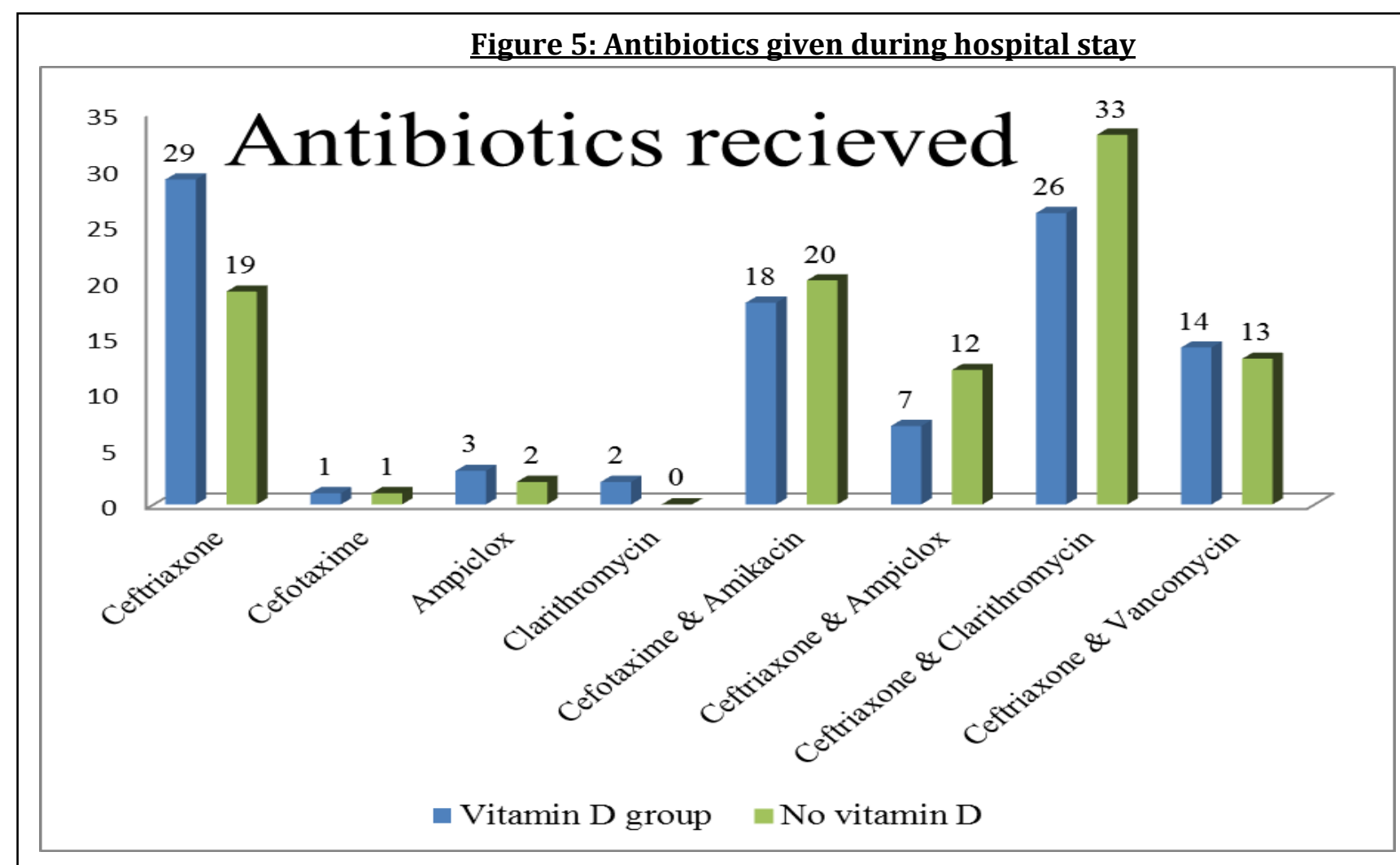

Table 2: Analytical statistics showing results of chi square test

\begin{tabular}{|c|c|c|c|c|}
\hline Symptoms & Intervention & Number & $\begin{array}{l}\text { Chi sq. } \\
\text { value }\end{array}$ & P value \\
\hline \multirow[t]{3}{*}{$1^{\text {st }}$ month } & Total & 22 & - & - \\
\hline & Vitamin D given & 4 & \multirow[b]{2}{*}{10.0} & \multirow[b]{2}{*}{0.002} \\
\hline & No vitamin D & 18 & & \\
\hline \multirow[t]{3}{*}{$2^{\text {nd }}$ month } & Total & 12 & - & - \\
\hline & Vitamin D given & 4 & \multirow[b]{2}{*}{1.4} & \multirow[b]{2}{*}{0.23} \\
\hline & No vitamin D & 8 & & \\
\hline \multirow[t]{3}{*}{$3^{\text {rd }}$ month } & Total & 2 & - & - \\
\hline & Vitamin D given & 0 & \multirow[b]{2}{*}{2.0} & \multirow[b]{2}{*}{0.16} \\
\hline & No vitamin D & 2 & & \\
\hline
\end{tabular}

Table 3: Analytical statistics showing t test of mean difference among Vit $D$ group and No vitamin group (Placebo)

\begin{tabular}{|c|c|c|c|c|c|}
\hline & Mean (days) & $\begin{array}{c}\mathrm{p} \text {-value } \\
\text { (for ' } \mathrm{t} \text { '- test of mean difference) }\end{array}$ & $\begin{array}{c}\text { SD } \\
\text { (days) }\end{array}$ & $\begin{array}{c}\text { Median } \\
\text { (days) }\end{array}$ & $\begin{array}{l}\text { Range } \\
\text { (days) }\end{array}$ \\
\hline Total & 5.9 & - & 2.8 & 5.7 & $1.1-14.7$ \\
\hline Vitamin D group & 5.7 & \multirow[t]{2}{*}{0.28} & 2.7 & 5.3 & $1.3-14.7$ \\
\hline No vitamin $\mathrm{D}$ & 6.1 & & 2.8 & 5.7 & $1.1-14.4$ \\
\hline
\end{tabular}




\section{Analytical statistics}

Vitamin D supplementation/ non supplementation group versus Recurrence and time. Both the groups which were randomly allocated with and without intervention with vitamin D were followed at the end of $1^{\text {st }}, 2^{\text {nd }}$ and $3^{\text {rd }}$ month after discharge and efficacy of vitamin $D$ on recurrence was studied. Table 2 and figure 6 illustrate details on efficacy of vitamin D on prevention of recurrence of pneumonia over 3 months duration after discharge.

\section{Figure 6: Repeat episode of pneumonia showing efficacy of vitamin D}

Repeat episodes of pneumonia

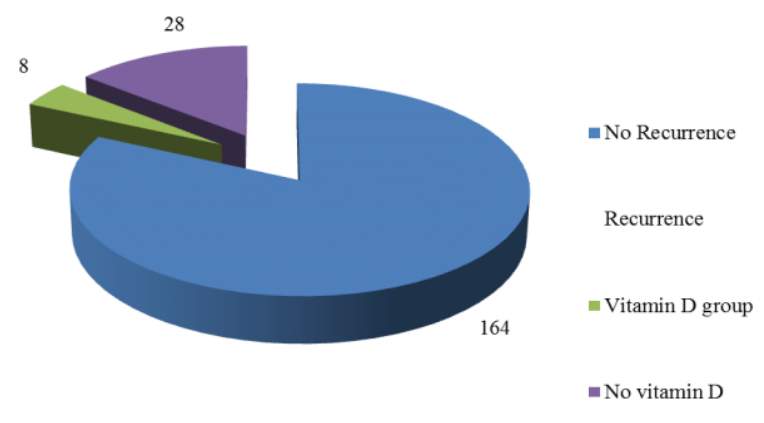

In first month follow up out of 200 children 22 had repeat episode of pneumonia and were labeled as recurrence. The group which got vitamin $\mathrm{D}$ supplementation had less recurrence $(n=4)$ as compared to the group which got only conventional therapy $(n=18)$. The relationship of recurrence of pneumonia with vitamin D supplementation was statistically significant at first month $(\mathrm{p}=0.002)$.
In second month follow up 12 children had recurrence among which vitamin $\mathrm{D}$ group $(n=4)$ had less recurrence than the other group $(n=8)$, but without statistical significance $(p=0.23)$.

At the end of third month only 2 children had recurrence and both of them lying on nonvitamin D group. However, the association was not significant $(\mathrm{p}=0.16)$

So the overall recurrence rate of pneumonia was less in group with vitamin D supplementation than the group without supplementation (Tabe $2 \&$ figure 6).

Mean duration of hospital stay was 5.9 days. Some of the patients were even discharged immediately after 24 hours whereas some stayed for upto 15 days. The mean duration of stay for vitamin D group was 5.7 days whereas for non-vitamin group was 6.1 days clearly stating that vitamin D group had lesser days of admission (Table 3). Although having numerical strength in favor of vitamin D group statistically the relationship between hospital stay and intervention was not significant $(\mathrm{p}=0.28)$.

\section{DISCUSSION}

Children with vitamin D deficiency and rickets are more likely to have pneumonia and respiratory tract infections [7]. On exposure of the human skin to Ultraviolet light from the sun, it synthesizes most of the vitamin D required in the body. Other sources are egg yolk, fatty fish such as tuna, sardines or cod liver oil [8]. The binding of vitamin D to its receptors results in increased intracellular formation of antimicrobial compounds, such as cathelicidins which serve a critical role in innate immunity against invasive bacterial infection [9]. Charan et al 
reported that vitamin $\mathrm{D}$ induces monocyte differentiation and inhibits lymphocyte proliferation thus increasing the immunity. It also increases the phagocytic activity of macrophages [11]. In this meta-analysis of trials the incidence of respiratory tract infection was $21.7 \%$ in vitamin D group but $30.1 \%$ in the placebo group [11].

The present study was conducted to see the efficacy of vitamin D in the prevention of respiratory tract infection especially pneumonia. Vitamin D has been related to have beneficial effects in many of the medical conditions like pneumonia, influenza, asthma, tuberculosis, autoimmune diseases, cardiovascular diseases and even malignancy [11-14]. Many trials have been done to determine the beneficial effects of vitamin D in different countries other than Pakistan. Our trial was the first randomized trial done in Pakistan to determine the role of vitamin D in children with pneumonia.

In this study mean age of the children admitted with pneumonia was 7.5 months. Among the children admitted in hospital most of the patients presented with fast breathing, cough and fever. Majority of the patients had crepts on chest auscultation which was consistent with the diagnosis of pneumonia [15-16].

In the present study the antibiotics received by both the groups with vitamin $\mathrm{D}$ or without vitamin $\mathrm{D}$ intervention were almost same which have checked the bias that could have probably occurred due to different antibiotics. The result of this trial has shown that supplementation with vitamin $\mathrm{D}$ in children with pneumonia, in addition to the appropriate antimicrobials significantly decreases the new episodes of pneumonia over 3 month period. However, there was no statistical difference in the duration of hospitalization between both groups of children. From this we can conclude that vitamin D supplementation in a high dose may not immediately help in recovery from pneumonia, but it can definitely prevent further episodes of new pneumonia. The findings were comparable with other studies done which showed similar results $[12,17]$.

The study by Manaseki-Holland et al showed that supplementing vitamin D in children with pneumonia reduces the repeat episodes of pneumonia within the next 90 days. The repeat episode risk was lesser in the group who received vitamin $\mathrm{D}$ in comparison to the group who did not (45\% vs. 58\%) [12]. A systematic review and meta-analysis by Charan et al showed that the events of respiratory tract infections are greatly reduced in those with vitamin D supplementation as compared to placebo [11]. One such study from Japan using vitamin D 1,200 IU/day had shown a significant decline of influenza among school children [18].

Similar to our study another Indian study by Choudhary and Gupta, used vitamin D for 5 days and compared with placebo in cases with pneumonia showed there is no effect in the time of recovery from the disease [19]. Another study from Afghanistan on the role of supplementing vitamin D in the incidence of childhood pneumonia and its severity, showed no additional beneficial effect of vitamin $\mathrm{D}$ when given to children with pneumonia [9].

A systematic review done by Das et al discussed the ineffectiveness of vitamin $D$ in pneumonia comparing two separate randomized trials [20]. One of the trial had used a single dose [12] whereas the other had 
used multiple doses with daily dosing schedule [19]. The reason for such result on supplementing vitamin D might be due to improper dose or the duration of use. It may indicate real therapeutic ineffectiveness of vitamin D in pneumonia. Regarding the dose it has been shown that daily dose schedule has a better therapeutic effect than a large bolus dose and there have been biological explanations to a smaller effect when using a bolus schedule of vitamin D [21-24].

As malnutrition is more prevalent in developing world, the malnourished children are at higher risk of deficiencies of other micronutrients such as calcium and vitamin A, both of which could modify effects of vitamin D supplementation [22]. As our study had more than $60 \%$ of children with some degree of malnutrition, results of this study may not be applicable to wellnourished population.

As our study has demonstrated that supplementing vitamin $\mathrm{D}$ has a protective effect in children with pneumonia, it is consistent with the suggested role of vitamin D on enhancing the immunity. There is increasing evidence that the biologically active metabolite of vitamin i.e. 1, 25dihydroxy vitamin $\mathrm{D}\left(1,25(\mathrm{OH})_{2} \mathrm{D}\right)$, has a crucial role to play in the innate immune system of human [24]. There is enhanced production of the 1-alpha-hydroxylase enzyme (CYP27B1) which is responsible for the local conversion of 25 - hydroxyvitamin $\mathrm{D}$ to $1,25(\mathrm{OH})_{2} \mathrm{D}$ [25]. This active form of vitamin $\mathrm{D}$ production further induces the expression of cathelicidin, thus enhancing the host's innate immunity against the microorganisms [25]. The activation of toll like receptors (TLRs) leads to accelerated release of antimicrobial proteins (AMPs) like cathelicidin by the innate immunity, which has a significant role to recognize the pathogens by human monocytes, macrophages and epithelial cells.

Prevention of the repeat episodes of pneumonia in children has possible benefit of improving the general health condition and reducing the overall burden of the disease. This study has important strengths. Firstly, It was a randomized control trial and the outcomes were measured by experienced pediatricians and IMCI clinical definitions were used along with radiological evidence for the diagnosis for pneumonia. These made this study more powerful when compared to other studies which used only the clinical or radiological criteria for pneumonia $[11,13$, 26].

\section{CONCLUSION}

This randomized control trial has proved that supplementing vitamin D in a dose of 100,000 IU supplementation can diminish the repeat episodes of pneumonia in children. As Pakistan has a high prevalence of vitamin D deficiency, supplementation of vitamin D in the future to children diagnosed as pneumonia can be recommended. Similarly, supplementation of vitamin D in children with pneumonia can be easily implemented in the developing countries with high prevalence of vitamin D deficiency. As pneumonia is the leading cause of mortality among children less than 5 years of age in developing countries, the prevention of disease can reduce the morbidity and mortality from the disease. Such supplementation may play an important role in reducing the major infection in children. However, this role is further needed to be proven by doing more trials in even larger and more diversified settings and the results after supplementing vitamin D need to be 
investigated to assess its role to improve the child health globally.

\section{ACKNOWLEDGEMENT}

\section{We are grateful to Department of Pediatrics, King Edward Medical University, Lahore, Pakistan for their support.}

\section{REFERENCES}

1. Barson WJ. Clinical features and diagnosis of community-acquired pneumonia in children. Available from:

http://www.uptodate.com/contents/epidemiologypathogenesis-and-etiology-of-pneumonia-in-children. [Assessed $3^{\text {rd }}$ April 2013]

2. Rudan I, Boschi-Pinto C, Biloglav Z et al. Epidemiology and etiology of childhood pneumonia. Bulletin of the World Health Organization 2008; 86(5): 408-416.

3. World Health Statistics WHO. Available at: http://www.who.int/gho/publications/world_health_stat istics/EN_WHS2013_Full.pdf [Assessed on: 2013 March 15]

4. You D, Jones G, Wardlaw T. WHO Levels and Trends in Child Mortality Report. A report prepared at UNICEF Headquarters on behalf of United Nations Inter-agency Group for Child Mortality Estimation 2011.

5. Pakistan Demographic and Health Survey. National Institute of Population Studies. Islamabad, Pakistan 2012 13.

6. Das J \& Zulfiqar A. Bhutta. Scale-Up Plan For Essential Medicines For Child Health. Diarrhoea, Pneumonia and Malaria, Pakistan. Aga Khan University, Karachi 2011.

7. Yakoob MY \& Bhutta ZA. Vitamin D supplementation for preventing infections in children less than five years of age (Protocol). The Cochrane Library 2010; 11.

8. WHO. e-Library of Evidence for Nutritional Actions (eLENA); Vitamin D supplementation to improve treatment outcomes among children diagnosed with respiratory infections; WHO; April 2011. Available at: http://www.who.int/elena/titles/bbc/vitamind_pneumo nia children/en/index.html [Assessed on: 2013 March 5].

9. Manaseki-Holland S, Qader G, Masher MI et al. Effect on the incidence of pneumonia of vitamin D supplementation by quarterly bolus dose to infants in Kabul: a randomized controlled superiority trial. Lancet 2012; 379: 1419-1427.

10. Mayo Clinic. Patient Care and Health Info; Drugs and supplements Vitamin D; Nov. 2013. Available at: http://www.mayoclinic.org/drugs-supplements/vitamind/dosing/hrb-20060400.html [Assessed on 2014 March 1].

11. Charan J, Goyal JP, Saxena D, Yadav P. Vitamin D for prevention of respiratory tract infections: A systematic review and meta-analysis. Journal of Pharmacology and Pharmacotherapeutics 2012; 3(4): 300-303.
12. Manaseki-Holland S, Qader G, Masher MI et al. Effects of vitamin D supplementation to children diagnosed with pneumonia in Kabul: a randomized controlled trial. Tropical Med and Int Health 2010; 15(10): 1148-1155.

13. Roth DE, Jones AB, Prosser C, Robinson J L, Vohra S. Vitamin $\mathrm{D}$ receptor polymorphisms and the risk of acute lower respiratory tract infection in early childhood. J of Infectious Dis 2008; 197: 676-680.

14. Holick MF. Sunlight and vitamin D for bone health and prevention of autoimmune diseases, cancers and cardiovascular disease. American J of Clinical Nutri 2004; 80: $1678 S$ - 88S.

15. Behrman RE, Kliegman RM and Jenson HB, Stanton BF. Chapter 400, In : Nelson Textbook of Pediatrics. 19th ed. Saunders, Philadelphia; 2011. pp 2088.

16. Miall L, Rudolf M, Levene M. Paediatrics at a Glance. $1^{\text {st }}$ ed. Blackwell Science Ltd; 2003. 54pp

17. Bergman $\mathrm{P}$, Norlin $\mathrm{AC}$, Hansen $\mathrm{S}$ et al. Vitamin D3 supplementation in patients with frequent respiratory tract infection: a randomized and double-blind intervention study. BMJ Open 2012; 2: 1-10.

18. Urashima M, Segawa T, Okazaki M, Kurihara M, Wada $Y$, Ida H. Randomized trial of vitamin D supplementation to prevent seasonal influenza $A$ in school children. The American J of Clinical Nutri 2010; 91(5): 1255-1260.

19. Choudhary N, Gupta P. Vitamin D. Supplementation for Severe Pneumonia- A randomized controlled trial. Ind Pedia 2012 ; 49: 449-454

20. Das RR, Singh M, Panigrahi I, Naik SS. Vitamin D supplementation for the treatment of acute childhood pneumonia: a systematic review. ISRN Pediatrics.2013; ID-459160: 1-7

21. Heaney RP. Vitamin D-baseline status and effective dose. The New England Journal of Med 2012; 367(1): 77-78.

22. Martineau AR. Bolus-dose vitamin D and prevention of childhood pneumonia. The Lancet 2012; 379(9824): 1373-1375.

23. Hollis BW. Short-term and long-term consequences and concerns regarding valid assessment of vitamin D deficiency: comparison of recent food supplementation and clinical guidance reports. Current Opinion in Clinical Nutrition and Metabolic Care 2011; 14(6): 598-604.

24. Bikle DD. Vitamin D and the immune system: role in protection against bacterial infection. Current Opinion in Nephrology and Hypertension 2008; 17(4): 348-352.

25. Liu PT, Stenger S, Wenzel L, Tan BH et al. Toll-Like Receptor Triggering of a Vitamin D-Mediated Human Antimicrobial Response. Science 2006; 311: 1770.

26. Banajeh SM. Nutritional rickets and vitamin D deficiency associations with the outcomes of childhood very severe pneumonia: a prospective cohort study. Pediatric Pulmonology 2009; 44: 1207-1215. 